\title{
MAPING THE SOIL FERTILITY OF BISANKHEL CATCHMENT OF CHITLANG VDC AND COMPARISON OF DIFFERENT GEO-SPATIAL INTERPOLATION TECHNIQUES
}

\author{
B. Bhusal ${ }^{1}$, S. Lamichhane ${ }^{2}$ and R.K. Shrestha ${ }^{1}$ \\ ${ }^{1}$ Institute of Agriculture and Animal Science, Lamjung Campus, Nepal \\ ${ }^{2}$ Soil Science Division, Nepal Agricultural Research Council \\ *bhusal.bivek.iaas@gmail.com
}

\begin{abstract}
The aim of this research work was to map the status of soil nutrients in the Bisankhel catchment of Chitlang VDC, Makawanpur, Nepal. The study area covered 1023.25 hectares of land, extending from $85^{\circ} 8^{\prime} 8.433^{\prime \prime} \mathrm{E}$ to $85^{\circ} 10^{\prime} 10.198^{\prime \prime} \mathrm{E}$ longitude and $27^{\circ} 37^{\prime} 24.2511^{\prime \prime} \mathrm{N}$ to $27^{\circ} 40^{\prime} 21.560^{\prime \prime} \mathrm{N}$ latitude. Total Nitrogen $(\mathrm{N})$, available Phosphorus(P), extractable Potassium (K), soil organic matter (SOM) and soil $\mathrm{pH}$ were measured for 50 soil samples collected using random sampling representing different land uses in the study area. Most of the samples were found very acidic where uplands (4.879 \pm 0.119$)$ were more acidic than lowlands (5.036 \pm 0.0973$)$. Most samples upon analysis were found to be medium in SOM and total N. SOM was slightly higher in lowlands $(3.385 \pm 0.256 \%)$ than in uplands $(3.05 \pm 0.206 \%)$. Total $\mathrm{N}$ was also slightly higher in lowlands $(0.145 \pm 0.00634 \%)$ than in uplands $(0.127 \pm 0.00639 \%)$. Similarly, Available P and K were found very high in majority of the soil samples. Available $\mathrm{P}$ was slightly higher in lowlands $(92.34 \pm 16.96 \mathrm{ppm})$ than in uplands $(71.58 \pm 15.47 \mathrm{ppm})$. However, extractable K was slightly more in uplands $(269 \pm 31.32 \mathrm{ppm})$ than in lowlands $(240.4 \pm 23 \mathrm{ppm})$. Spatial prediction using various interpolation methods was performed in ArcGIS 10.5 software platform using 'Geostatistical Analyst' extension. The predicted values in raster data structure were used for mapping the soil fertility status of the catchment. Different interpolation methods were evaluated following crossvalidation approach. Comparison of prediction errors was carried out to select the optimum prediction methods for the interpolation of soil nutrient values. Completely Regularized Spline and Ordinary Kriging methods were found to yield better prediction of soil nutrient status among the Deterministic and Kriging methods respectively. Soil $\mathrm{pH}$ being the limiting factor, $\mathrm{pH}$ control was necessary.
\end{abstract}

Key words: Geostatistics, GIS, Kriging, IDW, Splines, Soil fertility mapping

\section{INTRODUCTION}

Due to the lack of site specific fertilizer recommendation, the recommended dose of the fertilizers fails to achieve result as desired. Hence it is necessary to assess the fertility status of soil with the consideration of available nutrients in soils and to recommend the specific nutrients for the proper management of soil (Ramamurthy et al., 2009). Information on soil fertility status in crop field is very important and useful for fertilizer requirement and also to the specific management of the crop and soil (Malek et al., 2007). It has been documented very well that soils are not only thirsty but hungry too (Wani, 2008) meaning that besides soil and water conservation, if nutrient management issues are addressed, the productivity of a land is further enhanced. Inadequate fertilizer application limits crop yield, results in nutrient mining and causes soil fertility depletion. An excessive or imbalanced application not only wastes this limited costly resource, but also pollutes the environment. In the face of economic and environmental concerns, farmers face an increasing challenge of effective 
soil fertility management. An approach towards justifying such concerns is site specific nutrient management which considers spatial variations in nutrients status, thus cutting down the possibility of over or under use of fertilizer. Geographic information system (GIS) is a powerful tool which helps to integrate many types of spatial information such as agro-climatic zone, land use, soil management, etc. to derive useful information (Adornado and Yoshida 2008). Geographical Information System (GIS) has emerged that brings the representation of the world to the desktop by linking the data to geography from where the user can customize and display information. Functions of full GIS system vary from simply looking at aerial images and drawing outfield boundaries for determining area to developing complex maps with numerous overlays (Jonathon, 2002). Furthermore, GIS generated soil fertility maps serve as a decision support tool for nutrient management (Iftikar et al., 2010).

A number of studies on soil fertility mapping have been documented (Ravikumar et al., 2004). The accuracy of interpolation methods for spatially predicting soil properties has been analyzed in several studies. Kravchenko and Bullock (1999) compared inverse distance weighting (IDW), ordinary kriging and lognormal ordinary kriging for soil properties (Phosphorous (P) and Potassium (K)) from 30 experimental fields. They found that if ordinary kriging is more successful than IDW. Further, Laslett et al., (1987) also found ordinary kriging to be a better method than IDW for interpolating $\mathrm{pH}$. In fact, Laslett et al., (1987) judged splines to be a better than both IDW and kriging. In contrast, Gotway et al., (1996) observed better results than kriging for soil organic matter and Nitrogen when using IDW. Weber and Englund (1992) also found that IDW produced better results than kriging. Indicatively, Schloeder et al., (2001) observed that Ordinary Kriging (OK) and IDW were similarly accurate and effective methods, while thin-plate smoothing spline with tensions was not. But, such types of studies are at preliminary stage in case of Nepal.

The present study was carried out in Bisankhel catchment of Chitlang VDC at Makawanpur district with the objective to map the spatial distribution of soil fertility parameters and to compare among the interpolation techniques for their feasibility so as to contribute site specific nutrient management. Maps were prepared by the process of spatial interpolation where values at unsampled points within the map boundary were all predicted using the known values of sampled points. Among the various interpolation tools available, seven most used methods in mapping geochemical and soil properties i.e., Inverse Distance Weighting (IDW), Splines with Tension (SWT), Thin Plate Splines (TPS), Completely Regularized Spline (CRS), Ordinary Kriging (OK), Simple Kriging (SK) and Universal Kriging (UK) were followed in the study.

\section{MATERIALS AND METHODS}

The research was carried out at Bisankhel catchment in Chitlang VDC of Makawanpur district. The catchment boundary delineated using digital elevation model (DEM) of 20m spatial resolution was obtained from the GIS, Remote Sensing and Soil Survey unit of Soil Science Division, NARC. Within the catchment boundary, 50 sample points were determined through random sampling based on high resolution satellite imagery accessed via Google Earth Pro and their geographic locations were loaded into a handheld GPS device and were reached by navigating in the field using the GPS device. Composite sampling was carried out in each sample points using soil auger and were analyzed for $\mathrm{pH}$ value, organic matter, total Nitrogen, available Phosphorous and available Potassium content. 

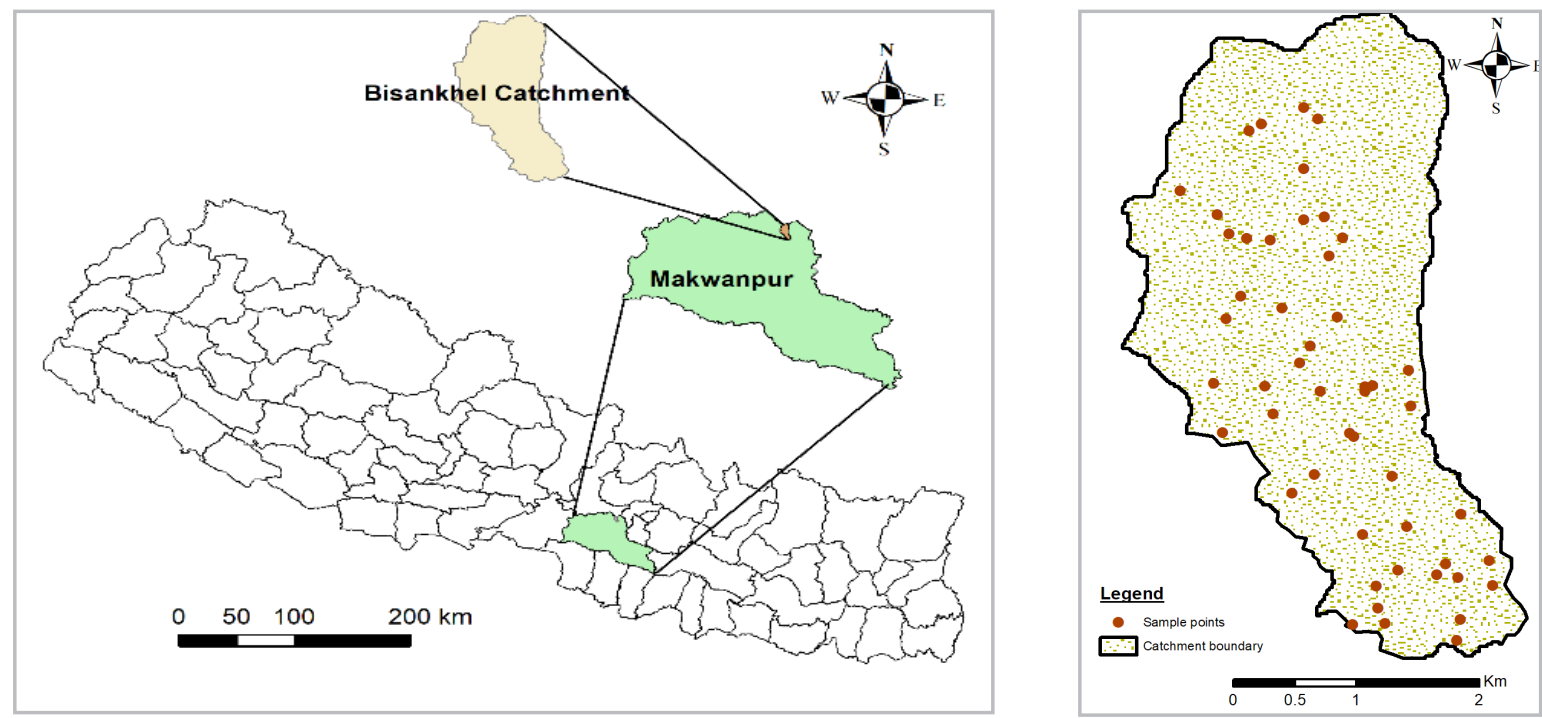

Figure 1: Location of study area (left) and sample points within the catchment (right)

The result of laboratory test along with the latitude and longitude were entered into Microsoft Excel sheet and saved as "Excel 97-2003 workbook" type i.e. supported on ArcMap platform. The excel data was further converted to ArcMap shapefile and added as a layer on ArcMap 10.5 platform software. The catchment boundary was also added as a layer. For each of the 5 parameters taken and 7 interpolation techniques followed, namely, Inverse Distance Weighting (IDW), Completely Regularized Spline (CRS), Spline with Tension (SWT), Thin Plate Spline (TPS), Ordinary Kriging (OK), Simple Kriging (SK) and Universal Kriging (UK), spatial prediction within the catchment boundary was carried out using 'Geostatistical Analyst' extension. Data layer thus formed was adjusted to the rectangular extent of the catchment boundary and then exported as raster file of '.tif' format with desired output cell size ( $5 \mathrm{~m}$ in the study) to a defined location. The raster file formed was then clipped to the extent of catchment boundary using clip tool for data management. The clipped raster file of '.tif' format was then saved to defined location and further used in map preparation. Color of the clipped map was changed to define the distribution of fertility parameters within the catchment and north arrow and scale bar was added to prepare desired map in the layout view of ArcMap 10.5 software platform. Thus, formed map was exported to image form and subsequently for each 5 fertility parameters and 7 interpolation methods, 35 maps in total were prepared. Furthermore, mean, standard error of mean, minimum, maximum, standard deviation and coefficient of variation were calculated for data of each fertility parameters using Geo-stat software. Comparison of prediction errors was carried out to select the optimum prediction methods for the interpolation of soil nutrient values. Also, digitation of land use map was carried out by visual interpretation of high resolution Google earth imagery in ArcMap 10.5 platform.

\section{RESULT AND DISCUSSION}

Most of the land of study area was covered by forest (52\%). Consisting of more than $27 \%$ of the total land area, uplands were dominating the lowlands among the non-forest cultivated area. Lowlands only covered about $14 \%$ of the total land area.

Majority of the samples i.e. 34 were found to be very acidic. As many as 37 samples were found to be medium in organic matter status. However, regarding the level of total Nitrogen, 44 soil samples showed medium status. When 30 samples showed very high value for Phosphorous 
content, fairly half of the samples i.e. 26 of them showed very high value for Potassium content. No samples were found with lower values for Potassium content. Among the 19 samples collected from uplands and 22 samples from lowlands, soil $\mathrm{pH}$ in uplands $(4.879 \pm 0.119)$ was lower than in lowlands $(5.036 \pm 0.0973)$. Organic matter was slightly more in lowlands $(3.385 \pm 0.256 \%)$ than in uplands $(3.05 \pm 0.206 \%)$. Total Nitrogen was also slightly more in lowlands $(0.145 \pm 0.00634 \%)$ than in uplands $(0.127 \pm 0.00639 \%)$. Similarly, Available $\mathrm{P}_{2} \mathrm{O}_{5}$ was also slightly more in lowlands $(92.34 \pm 16.96 \mathrm{ppm})$ than in uplands $(71.58 \pm 15.47 \mathrm{ppm})$. However, $\mathrm{K}_{2} \mathrm{O}$ was slightly more in up lands $(269 \pm 31.32 \mathrm{ppm})$ than in lowlands $(240.4 \pm 23 \mathrm{ppm})$. Overall, the soil nutrient status is appreciable, however, the soil acidity might be a limiting factor in nutrient uptake by the plants in the study area. Soil Phosphorous content values showed greater variation (91.16\%) among the samples while soil $\mathrm{pH}$ value showed least variation $(10.31 \%)$.

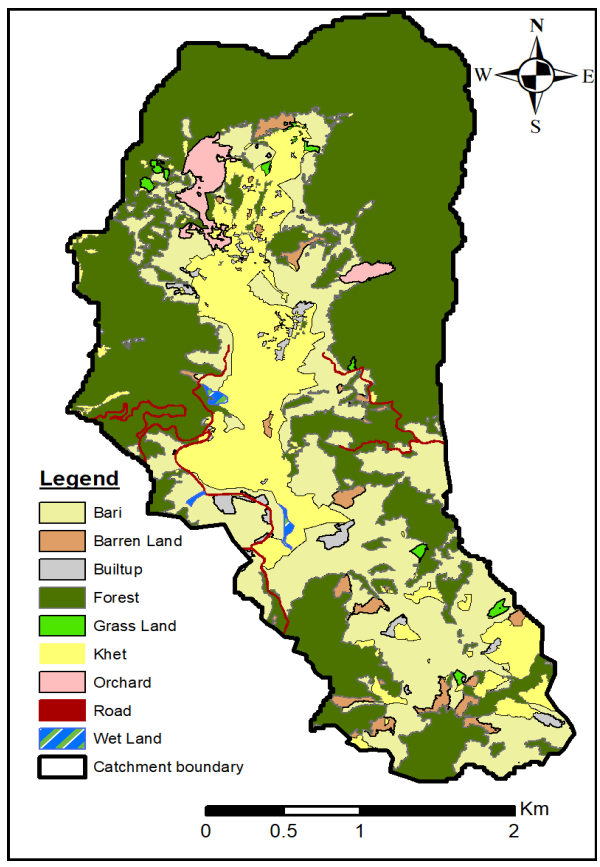

Table 1: Statistics on soil fertility parameters

\begin{tabular}{ccccccc}
\hline \multirow{2}{*}{ Statistic } & & \multicolumn{5}{c}{ Soil Fertility Parameters } \\
& & $\mathrm{Ph}$ & $\mathrm{OM}$ & $\mathrm{N}(\%)$ & $\mathrm{P}\left(\mathrm{kg} \mathrm{ha}^{-1}\right)$ & $\mathrm{K}\left(\mathrm{kg} \mathrm{ha}^{-1}\right)$ \\
\hline \multirow{3}{*}{ Mean } & Overall & 4.919 & 3.28 & 0.137 & 78.23 & 247.6 \\
& Lowland & 5.036 & 3.385 & 0.145 & 92.34 & 240.4 \\
& Upland & 4.879 & 3.05 & 0.127 & 71.58 & 269 \\
\hline \multirow{2}{*}{ Standard } & Overall & 0.0717 & 0.156 & 0.000411 & 10.9 & 17.1 \\
error of mean & Lowland & 0.0973 & 0.256 & 0.00634 & 16.96 & 23 \\
& Upland & 0.119 & 0.206 & 0.00639 & 15.47 & 31.32 \\
\hline \multirow{2}{*}{ Minimum } & Overall & 3.9 & 0.53 & 0.05 & 2 & 68 \\
& Lowland & 4.02 & 1.37 & 0.09 & 10 & 104.4 \\
& Upland & 3.9 & 0.53 & 0.05 & 2 & 92.4 \\
\hline \multirow{2}{*}{ Maximum } & Overall & 6 & 6.37 & 0.21 & 322 & 614.4 \\
& Lowland & 5.79 & 6.37 & 0.21 & 322 & 452.4 \\
& Upland & 6 & 4.01 & 0.17 & 223 & 614.4 \\
\hline \multirow{2}{*}{ Coefficient of } & Overall & 10.31 & 33.56 & 21.2 & 91.16 & 48.57 \\
Variation (\%) & Lowland & 9.06 & 35.53 & 20.56 & 86.15 & 44.88 \\
& Upland & 10.64 & 29.49 & 21.87 & 94.2 & 50.76 \\
\hline
\end{tabular}

Kriging methods use empirical semivariogram and covariance functions to estimate kriging predictors and standard errors, values that are not produced by deterministic interpolation methods (Johnston, Ver Hoef, Krivoruchko \& Lucas, 2001, Johnston, 2002). Each interpolation method was tested and the prediction errors from cross validation were collected. All of the deterministic methods produced mean prediction error and root mean square prediction error (RMSE) but additionally, kriging methods produced average standard error (ASE), mean standardized prediction error (MSE), 
and root mean square standardized prediction error (RMSSE). Thus, the kriging and non-kriging methods were analyzed separately during the data analysis to find out the best interpolation method (Johnston, 2002).

Table 2: Prediction error of soil parameters among Deterministic methods

\begin{tabular}{llrrrrr}
\hline \multirow{2}{*}{ Interpolation methods } & \multicolumn{5}{c}{ Soil Parameters } \\
\cline { 3 - 7 } & $\mathrm{pH}$ & & $\mathrm{OM}(\%)$ & $\mathrm{N}(\%)$ & $\mathrm{P}\left(\mathrm{kg} \mathrm{ha}^{-1}\right)$ & $\mathrm{K}\left(\mathrm{kg} \mathrm{ha}^{-1}\right)$ \\
\hline \multirow{2}{*}{$\mathrm{NDW}$} & $\mathrm{RMS}$ & -0.031 & 0.048 & -0.001 & -3.387 & 4.441 \\
& Mean & 0.54 & 0.943 & 0.024 & 55.592 & 128.931 \\
\hline \multirow{2}{*}{$\mathrm{CRS}$} & RMS & $\mathbf{0 . 0 0 3}$ & 0.029 & $\mathbf{0}$ & $\mathbf{- 1 . 7 9 1}$ & $\mathbf{- 0 . 6 8 1}$ \\
& Mean & $\mathbf{0 . 5 1 8}$ & 0.932 & $\mathbf{0 . 0 2 4}$ & $\mathbf{5 5 . 4 7 6}$ & $\mathbf{1 2 6 . 9 7 3}$ \\
\hline \multirow{2}{*}{$\mathrm{SWT}$} & RMS & 0.005 & $\mathbf{0 . 0 2 9}$ & 0 & -1.792 & -0.702 \\
& Mean & 0.521 & $\mathbf{0 . 9 3 2}$ & 0.024 & 55.476 & 127.445 \\
\hline \multirow{2}{*}{$\mathrm{TPS}$} & RMS & -0.036 & 0.101 & 0.001 & -2.56 & -3.206 \\
& Mean & 0.661 & 1.231 & 0.031 & 71.497 & 158.019 \\
\hline
\end{tabular}

Among the non-Kriging methods, for the prediction on $\mathrm{pH}$ values, CRS showed the prediction errors nearest to zero. Similarly, for the prediction of Organic matter content, prediction error values for SWT method were found nearest to zero and those for CRS followed them closely. For the prediction of Nitrogen, Phosphorous and Potassium content, prediction error values for CRS were found to be nearest to Zero and those for SWT method followed them closely as shown in the table. Thus, from the above observations, CRS method was found to be best and SWT method was found to be satisfactory among the non-Kriging methods. Laslett et al. (1987) also judged splines to be a better than IDW and CRS to be better among splines.

Table 3 (1): Prediction error of soil parameters among Kriging methods

\begin{tabular}{|c|c|c|c|c|c|c|}
\hline & & Units & Mean & $\begin{array}{c}\text { Mean standardized } \\
\text { (MS) }\end{array}$ & RMS & $\begin{array}{c}\text { RMS Standardized } \\
\text { (RMSS) }\end{array}$ \\
\hline \multirow{5}{*}{ 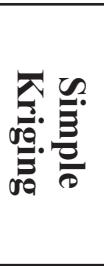 } & $\mathrm{pH}$ & & 0.006 & -0.014 & 0.551 & 1.800 \\
\hline & $\mathrm{OM}$ & \multirow{2}{*}{$\%$} & -0.053 & -0.039 & 0.963 & 0.966 \\
\hline & $\mathrm{N}$ & & 0.000 & 0.010 & 0.027 & 1.131 \\
\hline & $\bar{P}$ & \multirow{2}{*}{$\begin{array}{l}\mathrm{mg} \\
\mathrm{Kg}^{-1}\end{array}$} & -0.918 & -0.092 & 53.899 & 0.879 \\
\hline & $\mathrm{K}$ & & 0.015 & 0.001 & 118.765 & 1.009 \\
\hline \multirow{5}{*}{ 武产 } & $\mathrm{pH}$ & & 0.001 & 0.012 & 0.501 & 1.051 \\
\hline & $\mathrm{OM}$ & \multirow{2}{*}{$\%$} & 0.017 & 0.009 & 0.949 & 1.008 \\
\hline & $\mathrm{N}$ & & 0.000 & -0.008 & 0.026 & 1.092 \\
\hline & $\bar{P}$ & \multirow{2}{*}{$\begin{array}{l}\mathrm{mg} \\
\mathrm{Kg}^{-1}\end{array}$} & -0.503 & -0.012 & 53.415 & 1.068 \\
\hline & $\mathrm{K}$ & & -3.715 & -0.028 & 127.137 & 0.936 \\
\hline \multirow{5}{*}{ 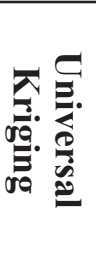 } & $\mathrm{pH}$ & & 0.001 & 0.012 & 0.501 & 0.949 \\
\hline & OM & \multirow{2}{*}{$\%$} & 0.017 & 0.009 & 0.949 & 1.008 \\
\hline & $\mathrm{N}$ & & 0.000 & -0.008 & 0.026 & 1.092 \\
\hline & $\mathrm{P}$ & \multirow{2}{*}{$\begin{array}{l}\mathrm{mg} \\
\mathrm{Kg}^{-1}\end{array}$} & -0.503 & -0.012 & 53.415 & 1.068 \\
\hline & $\mathrm{K}$ & & -3.716 & -0.028 & 127.137 & 0.936 \\
\hline
\end{tabular}


Table 3 (1): Prediction error of soil parameters among Kriging methods

\begin{tabular}{|c|c|c|c|c|c|}
\hline & & Units & $\begin{array}{l}\text { Average Standardized } \\
\text { error (ASE) }\end{array}$ & RMSS-1 & RMS-ASE \\
\hline \multirow{5}{*}{ 页: } & $\mathrm{pH}$ & & 0.501 & 0.800 & 0.050 \\
\hline & $\mathrm{OM}$ & \multirow{2}{*}{$\%$} & 1.015 & -0.034 & -0.052 \\
\hline & $\mathrm{N}$ & & 0.023 & 0.131 & 0.004 \\
\hline & $\mathrm{P}$ & \multirow{2}{*}{$\begin{array}{l}\mathrm{mg} \\
\mathrm{Kg}^{-1}\end{array}$} & 66.651 & -0.121 & -12.751 \\
\hline & $\mathrm{K}$ & & 117.587 & 0.009 & 1.178 \\
\hline \multirow{5}{*}{ 页 } & $\mathrm{pH}$ & & 0.514 & -0.051 & -0.013 \\
\hline & $\mathrm{OM}$ & \multirow{2}{*}{$\%$} & 0.945 & 0.008 & 0.005 \\
\hline & $\mathrm{N}$ & & 0.022 & 0.092 & 0.003 \\
\hline & $\mathrm{P}$ & \multirow{2}{*}{$\begin{array}{l}\mathrm{mg} \\
\mathrm{Kg}^{-1}\end{array}$} & 50.106 & 0.068 & 3.309 \\
\hline & $\bar{K}$ & & 135.310 & -0.064 & -8.173 \\
\hline \multirow{5}{*}{ 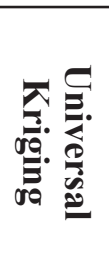 } & $\mathrm{pH}$ & & 0.514 & -0.051 & -0.013 \\
\hline & $\mathrm{OM}$ & \multirow{2}{*}{$\%$} & 0.945 & 0.008 & 0.005 \\
\hline & $\mathrm{N}$ & & 0.022 & 0.092 & 0.003 \\
\hline & $\mathrm{P}$ & \multirow{2}{*}{$\begin{array}{l}\mathrm{mg} \\
\mathrm{Kg}^{-1}\end{array}$} & 50.106 & 0.068 & 3.309 \\
\hline & $\overline{\mathrm{K}}$ & & 135.423 & -0.064 & -8.286 \\
\hline
\end{tabular}

On comparison among the Kriging methods, OK and UK both showed similar and the best performance for interpolating among OM content and Nitrogen content values. The Mean prediction error, Standardized Mean prediction error and Root Mean Square prediction error being closest to Zero showed the minimum biasness during prediction. Root Mean Square Standardized value being nearest to one showed variability among the data being accessed correctly and thus, better accuracy of standard errors. Similarly, Root Mean Square value being nearest to Average Standard Error confirmed that the predicted values don't deviate much from the measured values i.e. more valid standard errors. Likewise, OK showed best prediction regarding the Phosphorous content. But SK was found to perform best in interpolating the Potassium content of the study area. Regarding the interpolation for $\mathrm{pH}$ values, both OK and UK showed least biasness and more accuracy but only OK showed the least deviation of predicted values from the measured ones.

Further, values of Root Mean Square Standardized being greater than one and the Average Standard Error values being greater than Root Mean Square values, SK seemed comparatively overestimating the variability in predicting values for OM and $\mathrm{P}$ contents while OK and UK seemed overestimating the variability in predicting $\mathrm{pH}$ values and K content. Similarly, Root Mean Square Standardized being smaller than one and the Average Standard Error values being smaller than Root Mean Square values, SK seemed comparatively underestimating the variability in predicting values for $\mathrm{pH}, \mathrm{N}$ content and $\mathrm{K}$ content while $\mathrm{OK}$ and UK seemed underestimating the variability in predicting values for $\mathrm{OM}, \mathrm{N}$ and $\mathrm{P}$ content. Thus, variability among $\mathrm{N}$ content values seemed underestimated in the prediction with all interpolation methods carried.

Thus, from the table 3, Ordinary Kriging was found to be the best interpolation method for mapping with least biasness, more accurate standard errors and least deviation of predicted values from the measured ones among most of the parameters taken. Laslett et al. (1987) and Kravchenko and Bullock (1999) also found ordinary kriging to be a better method. 

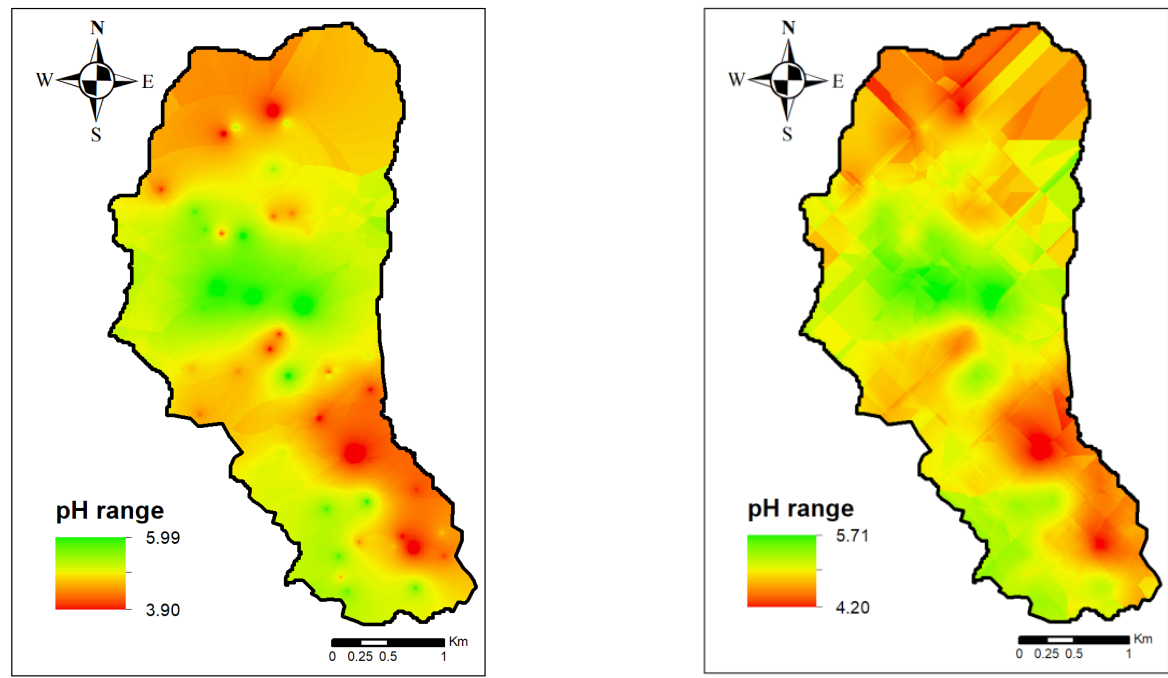

Figure 3: pH Map prepared through CRS (left) and OK (right) methods
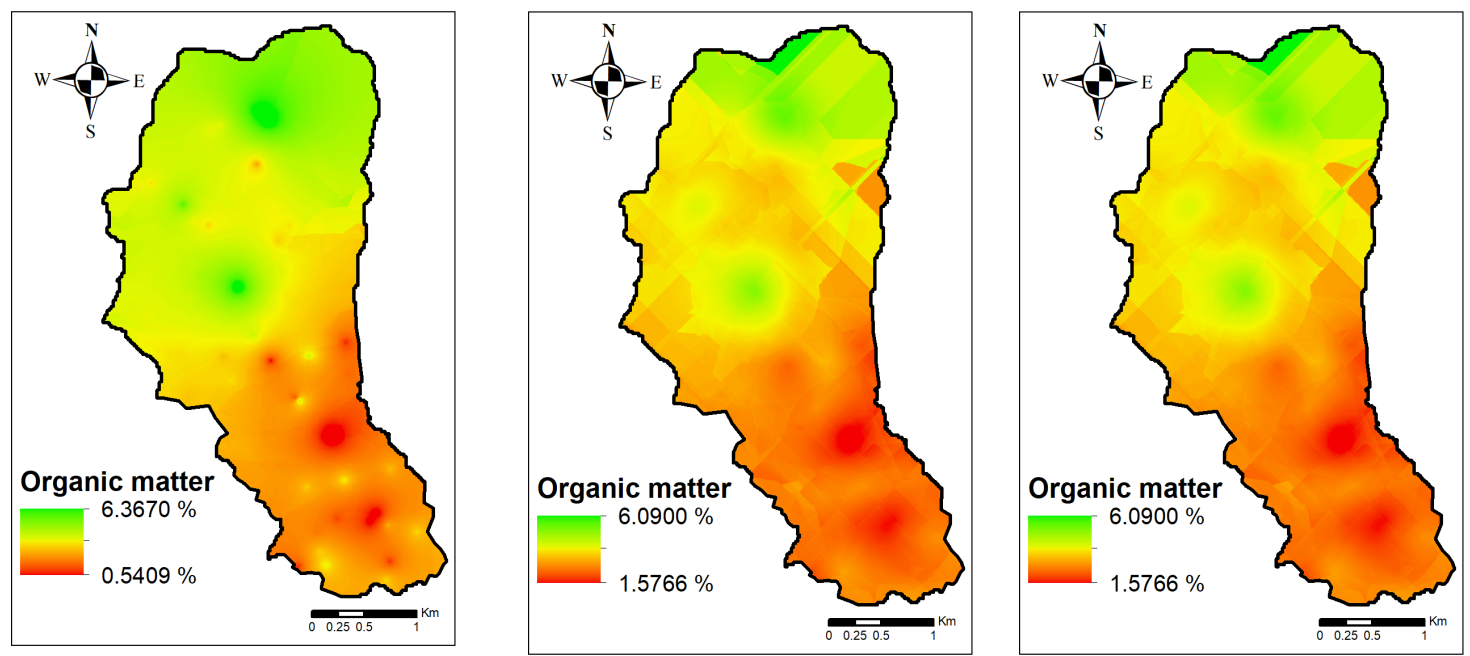

Figure 4: Organic matter map prepared through SWT (left), UK (middle) and OK (right) methods
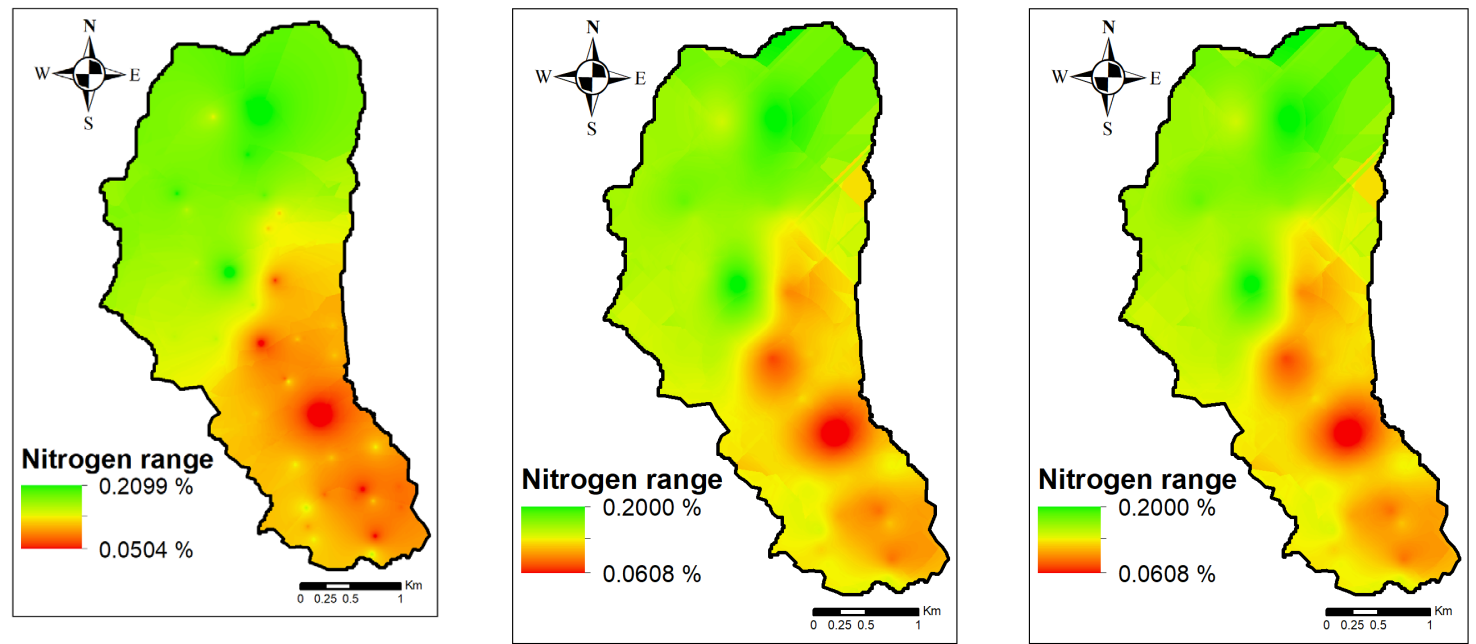

Figure 5: Total Nitrogen map prepared through SWT (left), UK (middle) and OK (right) methods 

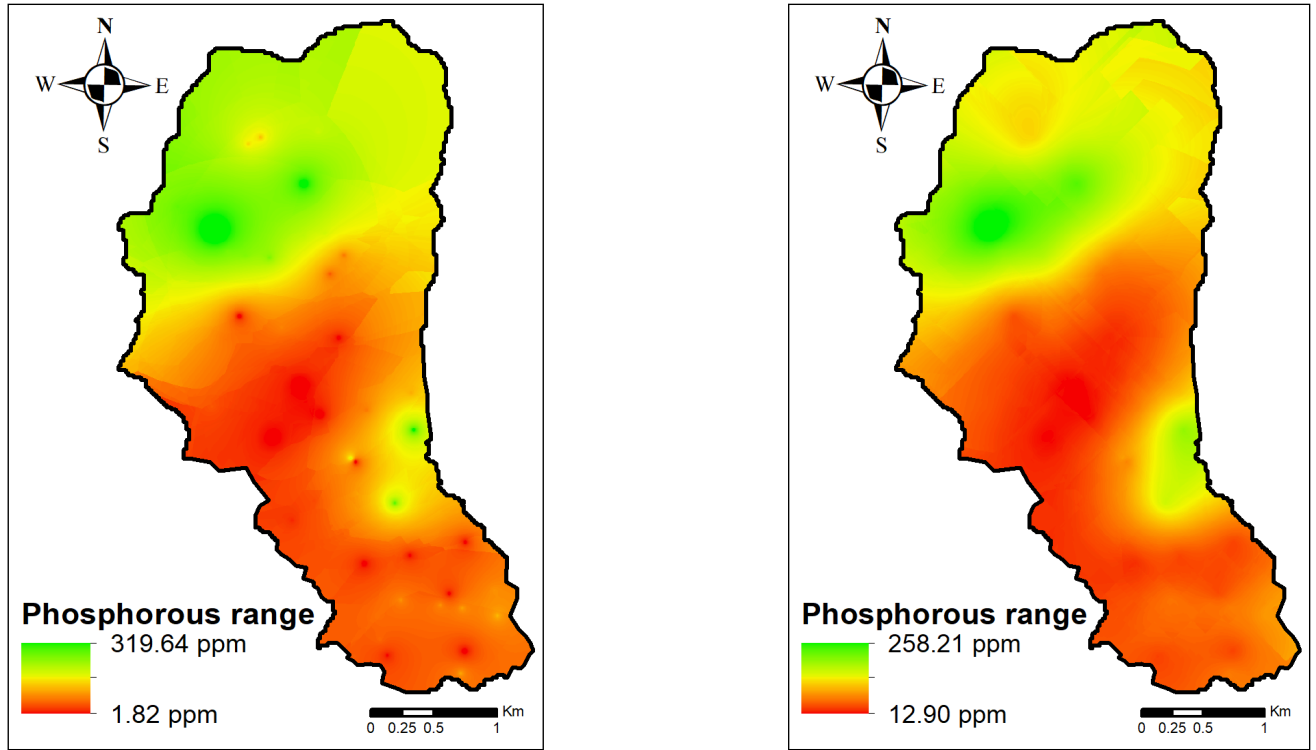

Figure 6: Available Phosphorous Maps prepared through CRS (left) and OK (right) methods
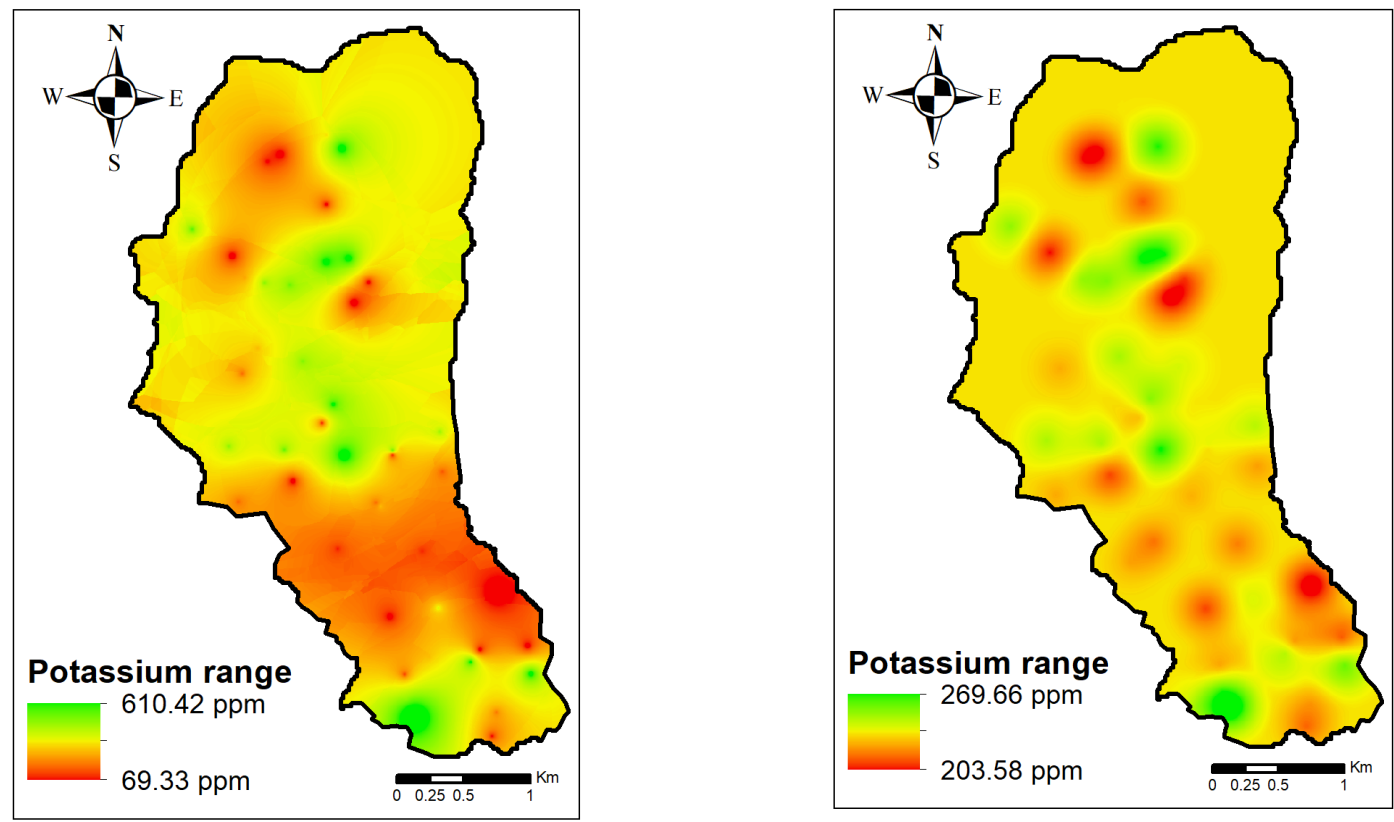

Figure 7: Available Potassium maps prepared through CRS (left) and OK (right) methods

\section{CONCLUSION}

From the research, it was concluded that the study area was very high in Potassium and Phosphorous content, moderate in organic matter and Nitrogen content and very acidic in $\mathrm{pH}$ range. Thus, $\mathrm{pH}$ being the limiting factor that hindered the availability of other nutrients though being in prosperous amount in the soil, acidity control is recommended for the Bisankhel catchment. 
Most of the applied interpolation methods gave similar results in terms of accuracy, without any of them being clearly better than the other methods. Though none of these methods are proved to be perfect for all situations, but for a particular situation, one can be the best for interpolation. Under the similar conditions, Completely Regularized Spline could be comparatively concluded the best interpolation method among the deterministic methods with least biasness among the data and Ordinary Kriging could be comparatively concluded the best among Kriging methods with least biasness, least deviated predictions from the measured values and most accurate standard errors for majority of the parameters carried. However, Spline with Tension is found best regarding Organic Matter content among the deterministic methods while Simple Kriging is found best regarding Potassium content among the Kriging methods.

\section{ACKNOWLEDGEMENT}

This work was undertaken as a partial fulfillment of Undergraduate Practicum Assessment of first author. Our sincere gratitude goes to Dr. Lal Prasad Amgain Ph.D. and whole Lamjung campus family for their tireless effort in smooth conduction of Undergraduate Practicum Assessment. We highly acknowledge the kind support of Soil Science Division, Nepal Agricultural Research Council.

\section{REFRENCES CITED}

Adornado, H.A., \& Yoshida, M. (2008). Crop suitability and soil fertility mapping using geographic information system (GIS). Agricultural Information Research, 17: 60-68.

Gotway, C.A., Ferguson, R.B., Hergert, G.W., \& Peterson, T.A., (1996). Comparison of kriging and inverse-distance methods for mapping soil parameters. Am. J. Soil Sci., 60: 1237-1247.

Iftikar, W., Chattopadhyaya, G.N., Majumdar, K. \& Sulewski, G.D. (2010) Use of village-level soil fertility maps as a fertilizer decision support tool in the red and lateritic soil zone of India. Better Crops, 94: 10-12.

Johnston, Kevin, Hoef, V., Jay, M., Krivoruchko, Konstantin, \& Lucas, N. (2001). Using ArcGIS Geostatistical Analyst. Environmental Systems Research Institute: Redlands.

Johnston, S. (2002). "Uncertainty in bathymetric surveys.” Coastal Hydraulics Engineering Technical Note CETN-IV, U.S. Army Corp of Engineer Research and Development Center: Vicksburg.

Kravchenko, A.N. \& Bullock, D.G. (1999). A comparative study of interpolation methods for mapping soil properties. J. Agronomy, 91: 393-400.

Laslett, G.M., McBratney, A.B., Pahl, P.J. \& Hutchinson, M.F. (1987). Comparison of several spatial prediction methods for soil $\mathrm{pH}$. J. Soil Sci., 38:325-341.

Malek, M.Y., Kamaruzaman, J. \& Mohd. H. I. (2007). Soil nutrient variability mapping in UiTM research station, Arau, Perlis Using Landsat TM7 and Geostatistical analysis, WSES Transaction on Signal Processing. Greece, 502:80-87.

Ramamurthy, V., Naidu, L.G.K., Ramesh Kumar, S.C., Srinivas S., \& Rajendra. (2009). Soil-based fertilizer recommendations for precision farming, Curr. Sci., 97: 641-646.

Ravikumar, M.A., Patil, P.L, .\& Dasog, G.S. (2004) Characterization and mapping of soil resources of 48A distributary of Malaprabha right bank command, Karnataka for land use planning. Karnataka Journal of Agricultural Sciences, 22: 81-88. 
Schloeder C A, N E Zimmerman \& Jacobs, M.J. (2001). Comparison of methods for interpolating soil properties using limited data. Soil Science Society of America Journal, 65: 470-479.

Wani, S.P. (2008). Taking soil science to farmers' doorsteps through community watershed management. Journal of the Indian Society of Soil Science, 56: 367377.

Weber, D., \& Englund, E. (1992). Evaluation and comparison of spatial interpolators. Math. Geol., 24: $381-391$. 